Supporting Information

\title{
Electrospinning of Near Gel Resin to Produce Crosslinked Fibrous Matrices
}

Pramod M. Gurave, Shweta Singh, Anilkumar Yadav, Bhanu Nandan, Rajiv K. Srivastava* Department of Textile and Fibre Engineering, Indian Institute of Technology Delhi, Hauz Khas, New Delhi-110016, INDIA

*Corresponding author: Email: rajiv@textile.iitd.ac.in,

Phone: 0091-11-26596680

Table of Contents:

\begin{tabular}{|c|l|}
\hline 1 & Figure S1. ${ }^{1} \mathrm{H}$ NMR spectra of BS2 nGR and fibres. \\
\hline 2 & Figure S2. ${ }^{1} \mathrm{H}$ NMR spectra of BS5 nGR and fibres. \\
\hline 3 & Table S1. Monomer conversion in nGR \\
\hline 4 & $\begin{array}{l}\text { Figure S3. SEM images of electrospun fibres at as-spun (A, B, C) and post heated (D, E, } \\
\text { F) condition with varying } X_{c} \text { of } 1 \%, 3 \% \text { and } 5 \% \text {, respectively at [M]/[I] = 700. }\end{array}$ \\
\hline 5 & $\begin{array}{l}\text { Figure S4. Optical pictures of electrospun fibres (A, B, C, D, E) produced using emulsions } \\
\text { with varying PVA concentration of 3 to 7\%, respectively. }\end{array}$ \\
\hline 6 & $\begin{array}{l}\text { Figure S5. SEM images of as-spun and post heat treated electrospun fibres with varying } \\
\phi_{d} \text { of 0.4 (A, B) and 0.5 (C, D), respectively. }\end{array}$ \\
\hline 7 & $\begin{array}{l}\text { Figure S6. Optical morphology of emulsions and respective electrospun fibres at varying } \\
\text { SDS concentration of } 1 \% \text { (A, B) and } 2 \% \text { (C, D). Range represents average size of droplets } \\
\text { of nGR in emulsion. }\end{array}$ \\
\hline 8 & $\begin{array}{l}\text { Figure S7. Optical images of nGR emulsions of EB6-EB11 with its droplet size } \\
\text { distribution. }\end{array}$ \\
\hline 9 & Figure S8. TEM micrographs of fibre morphology of EB7, EB8, EB10, EB11, respectively \\
\hline 10 & Table S2. Mechanical characteristics of electrospun matrices \\
\hline 11 & Figure S9. Graph showing gel content (Gc) of electrospun fibrous matrices. \\
\hline
\end{tabular}




\section{- Monomer conversion study}

The monomer conversion in near gel resin (nGR) samples was quantified by proton NMR using Equation S1.

Conversion $(\%)=\frac{A(a)}{A(a)+A\left(a^{\prime}\right)} \times 100$ equation $\mathrm{S} 1$

Where, $\mathrm{A}(\mathrm{a})$ and $\mathrm{A}\left(\mathrm{a}^{\prime}\right)$ are the areas under the peak correspond to proton (a) and (a').

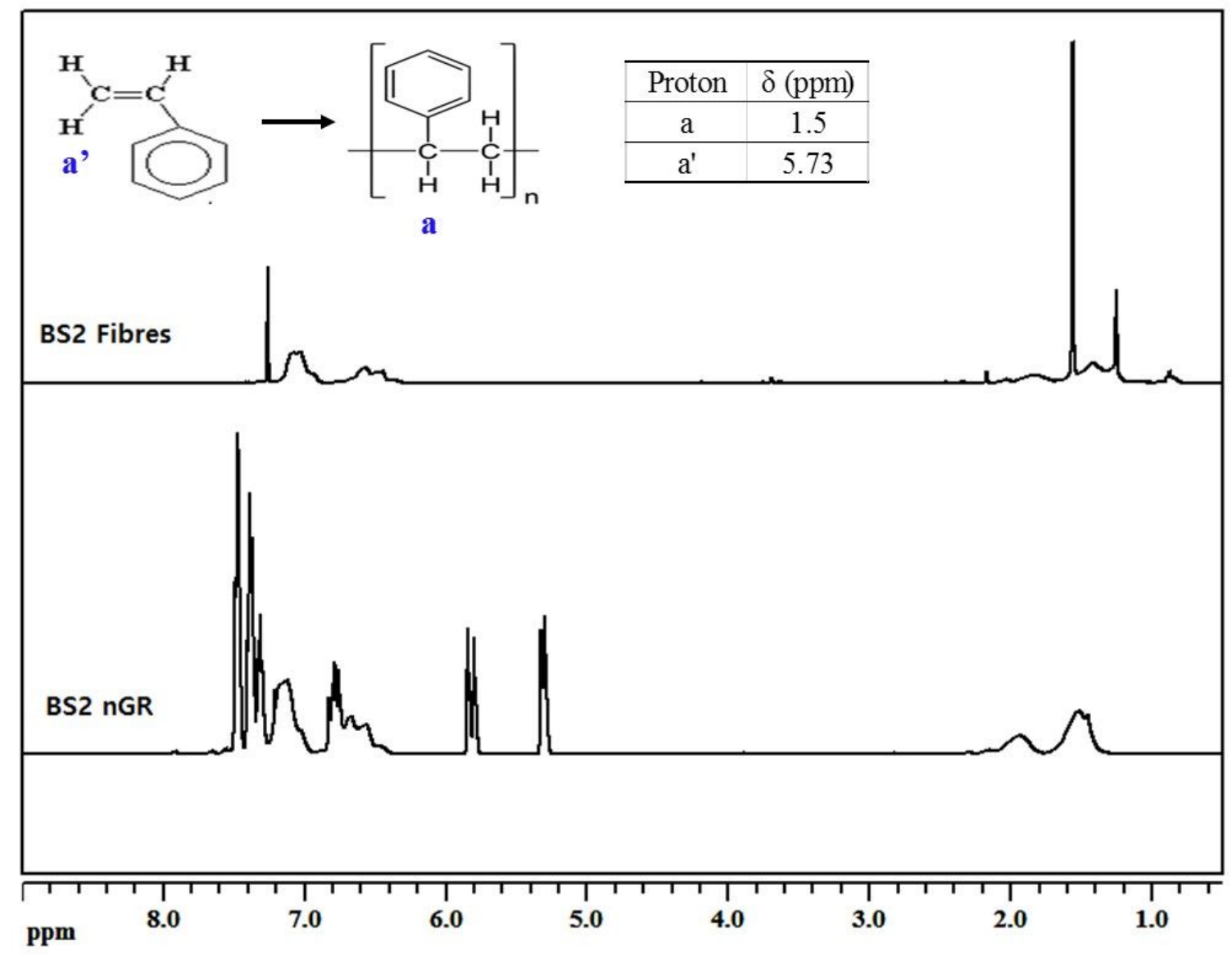

Figure S1. ${ }^{1} \mathrm{H}$ NMR spectra of BS2 nGR and fibres. 


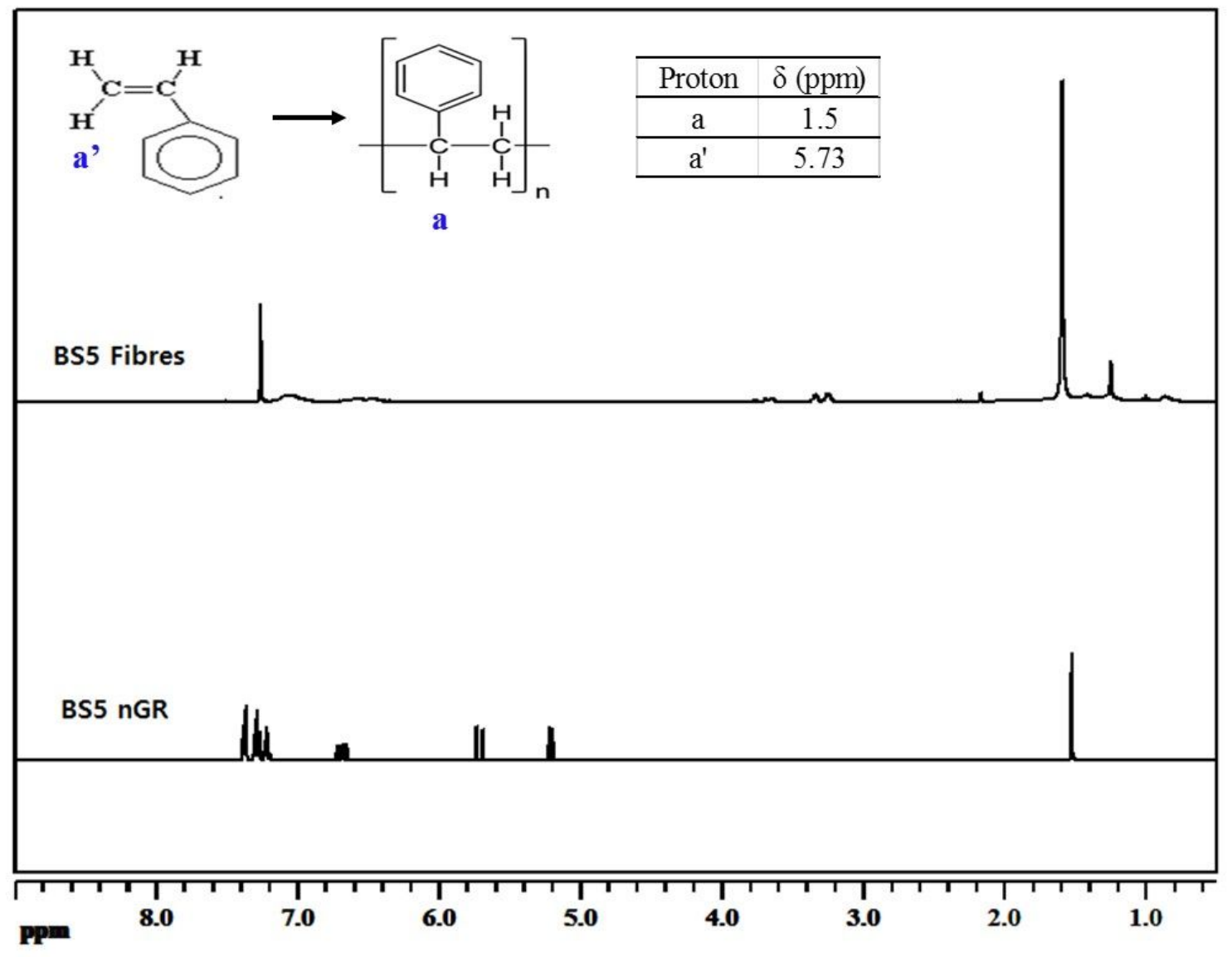

Figure S2. ${ }^{1} \mathrm{H}$ NMR spectra of BS5 nGR and fibres.

Table S1. Monomer conversion in nGR

\begin{tabular}{|c|c|}
\hline Sample ID & Monomer conversion (\%) \\
\hline BS1 & 24 \\
\hline BS2 & 36 \\
\hline BS3 & 19 \\
\hline BS4 & 14 \\
\hline BS5 & 12 \\
\hline
\end{tabular}



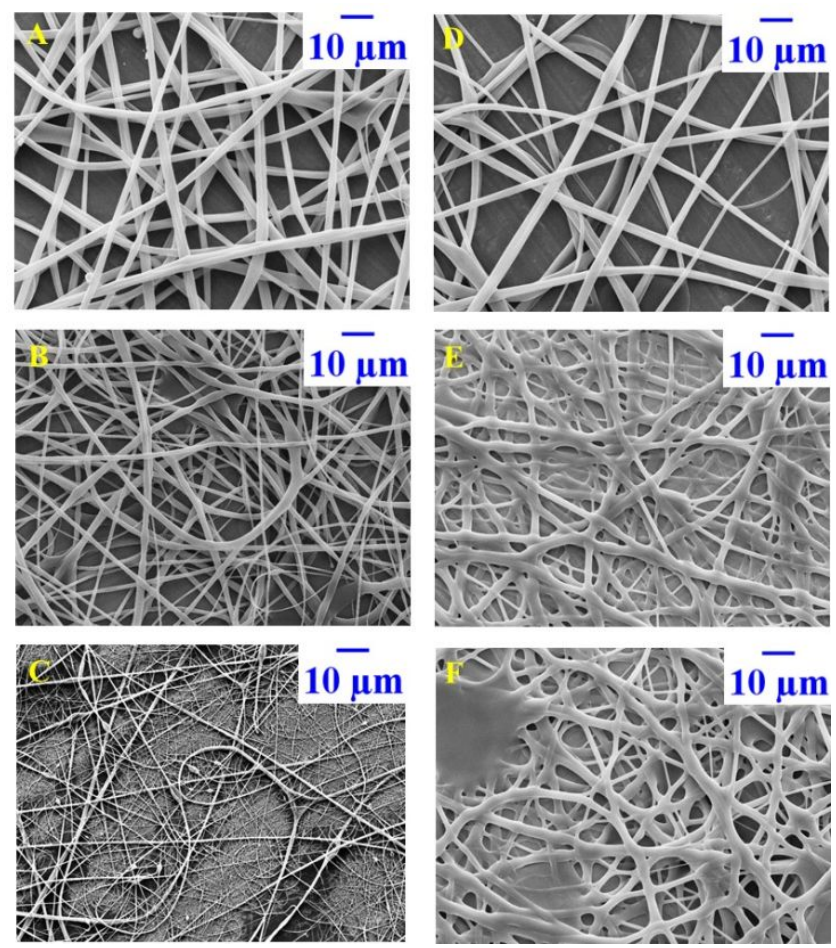

Figure S3. SEM images of electrospun fibres at as-spun (A, B, C) and post heated (D, E, F) condition with varying $X_{c}$ of $1 \%, 3 \%$ and $5 \%$, respectively at $[\mathrm{M}] /[\mathrm{I}]=700$.
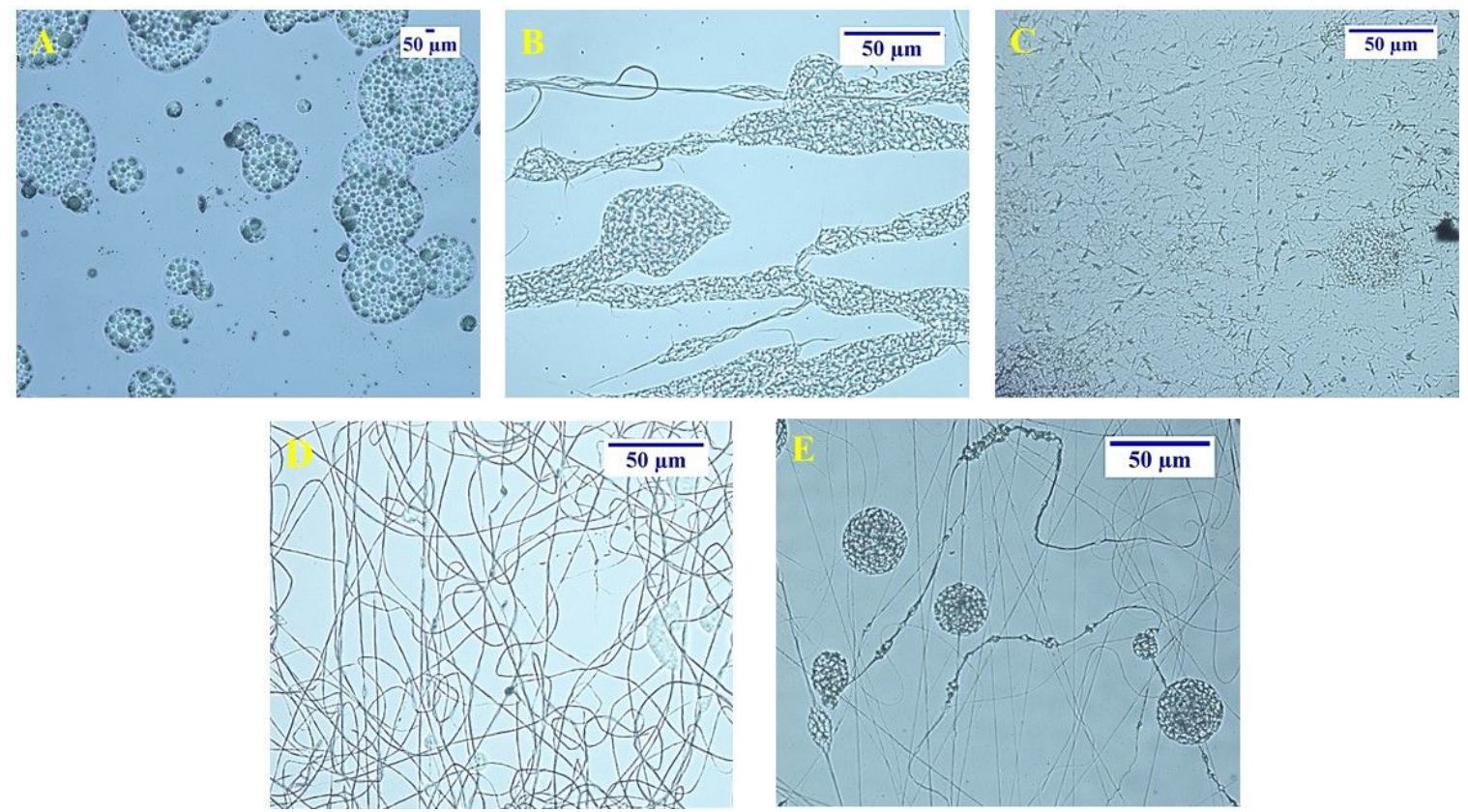

Figure S4. Optical pictures of electrospun fibres (A, B, C, D, E) produced using emulsions with varying PVA concentration of 3 to $7 \%$, respectively. 

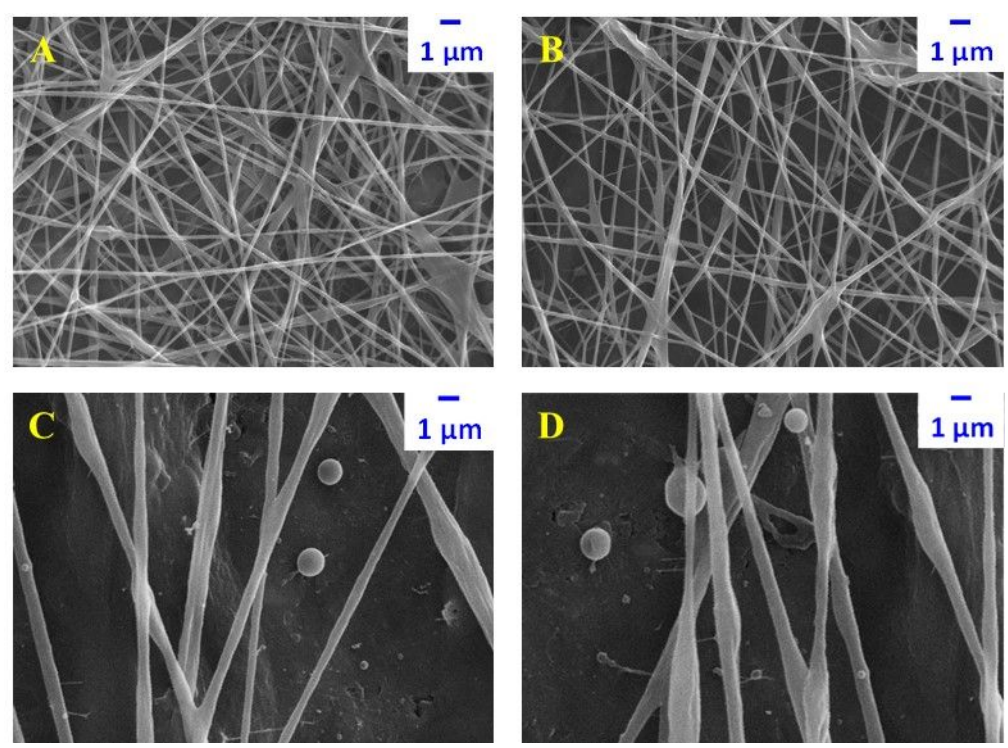

Figure S5. SEM images of as-spun and post heat treated electrospun fibres with varying $\phi_{d}$ of 0.4 $(\mathrm{A}, \mathrm{B})$ and $0.5(\mathrm{C}, \mathrm{D})$, respectively.
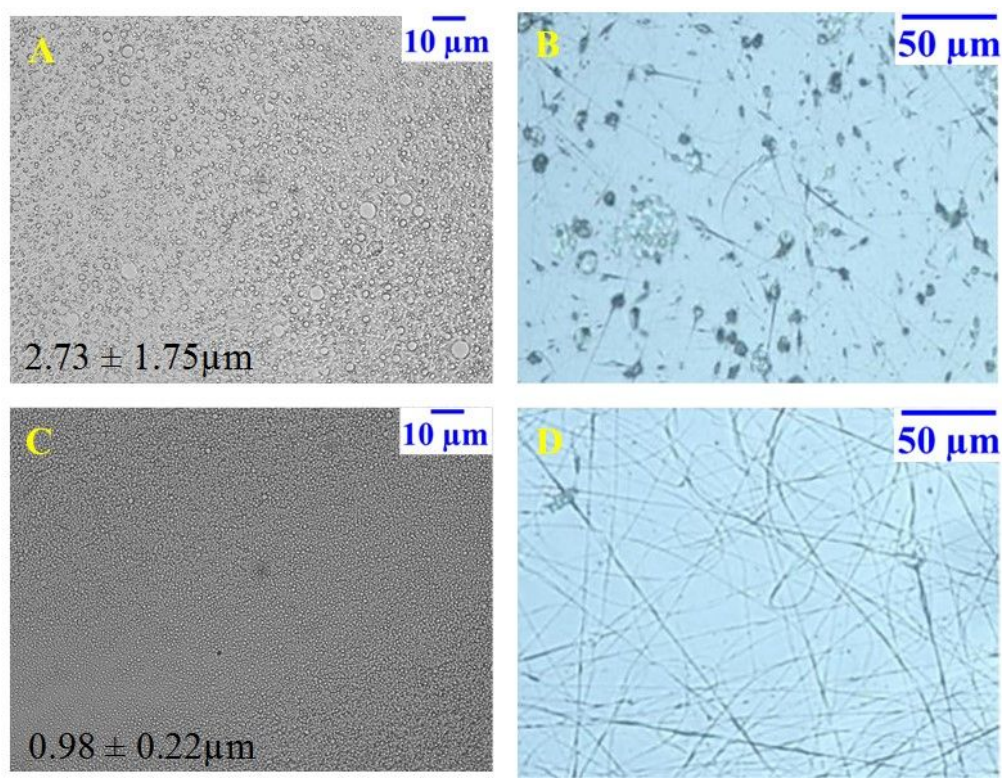

Figure S6. Optical morphology of emulsions and respective electrospun fibres at varying SDS concentration of $1 \%(A, B)$ and $2 \%(C, D)$. Range represents average size of droplets of nGR in emulsion. 

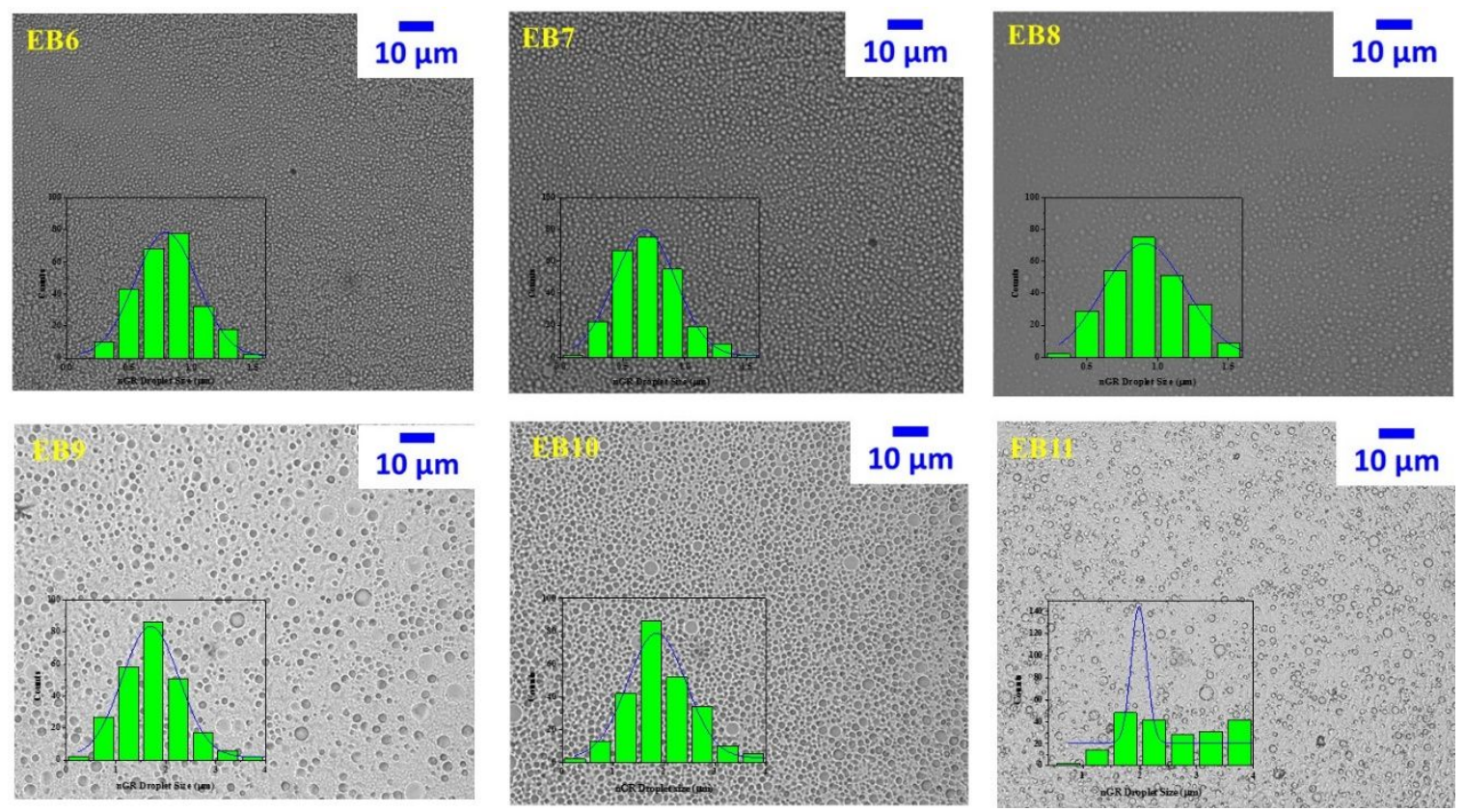

Figure S7. Optical images of nGR emulsions of EB6-EB11 with its droplet size distribution.
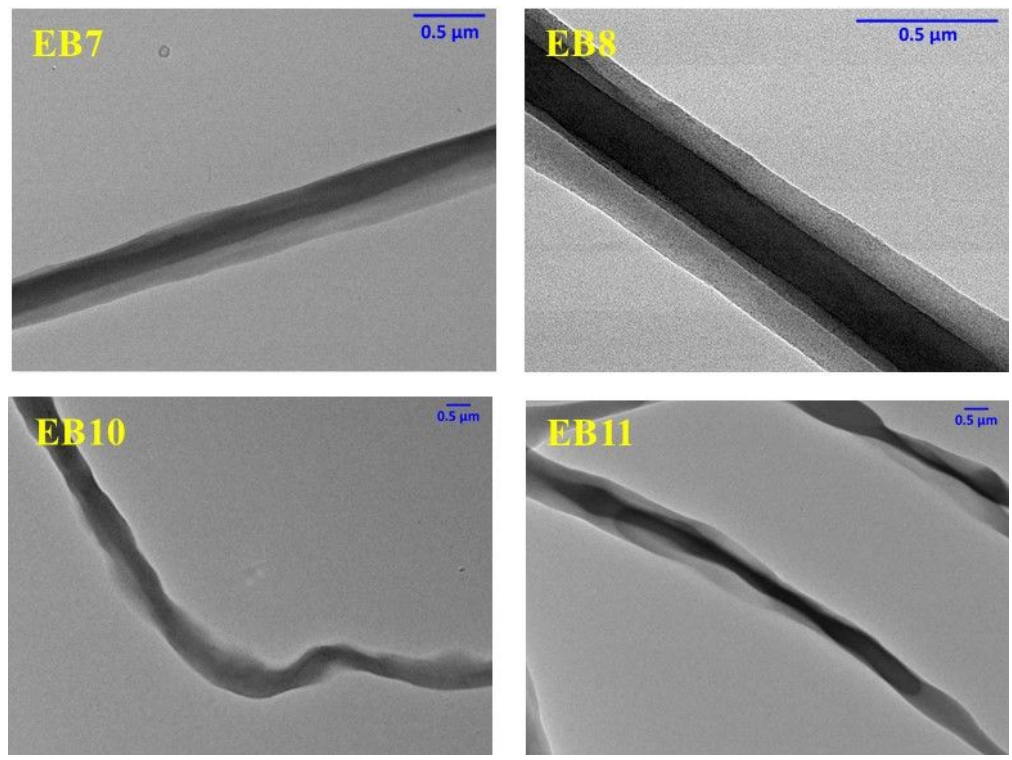

Figure S8. TEM micrographs of fibre morphology of EB7, EB8, EB10, EB11. 
Table S2. Mechanical characteristics of electrospun matrices

\begin{tabular}{|c|c|c|c|}
\hline Sample ID & $\begin{array}{c}\text { Young's Modulus } \\
\text { (MPa) }\end{array}$ & $\begin{array}{c}\text { Tensile Strength } \\
\text { (MPa) }\end{array}$ & $\begin{array}{c}\text { Extension } \\
\mathbf{( \% )}\end{array}$ \\
\hline EB6 & $0.06 \pm 0.01$ & $0.67 \pm 0.14$ & $9.46 \pm 0.68$ \\
\hline EB7 & $0.10 \pm 0.01$ & $0.83 \pm 0.13$ & $9.46 \pm 0.43$ \\
\hline EB8 & $0.10 \pm 0.01$ & $1.08 \pm 0.18$ & $9.47 \pm 0.52$ \\
\hline EB9 & $0.01 \pm 0.001$ & $0.15 \pm 0.09$ & $13.95 \pm 0.93$ \\
\hline EB10 & $0.01 \pm 0.001$ & $0.19 \pm 0.05$ & $13.96 \pm 1.03$ \\
\hline EB11 & $0.01 \pm 0.001$ & $0.23 \pm 0.09$ & $13.57 \pm 0.62$ \\
\hline
\end{tabular}

\section{- Study on Gel content $\left(\mathbf{G}_{\mathbf{c}}\right)$}

The gel content $\left(\mathrm{G}_{\mathrm{c}}\right)$ of electrospun fibres was measured through gravimetric method using equation S2.

$\mathrm{G}_{\mathrm{c}}(\%)=100-\left[\left(\frac{\mathrm{Mi}-\mathrm{Mf}}{\mathrm{Mi}}\right) \times 100\right]$ equation

\section{S2}

Where Mi and Mf correspond to initial dry weight of matrices and final dry weight of matrices treated in toluene for 24 hours at ambient conditions.

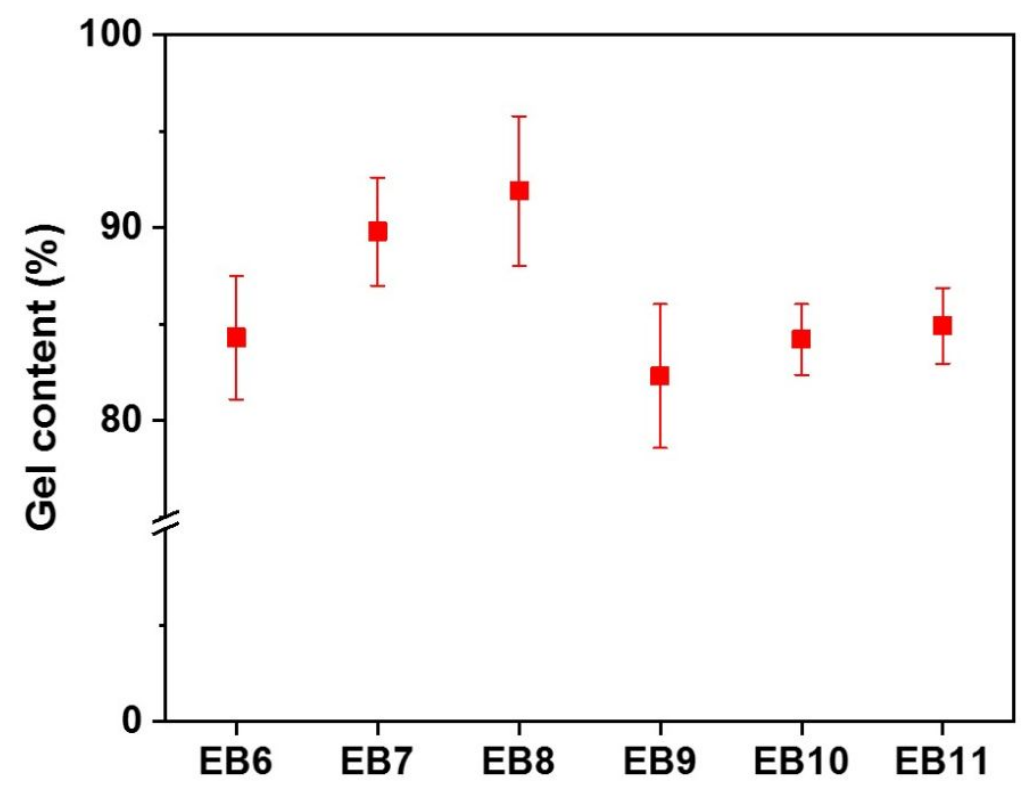

Figure S9. Graph showing gel content $\left(\mathrm{G}_{\mathrm{c}}\right)$ of electrospun fibrous matrices. 